\title{
Anemia prevalence and incidence and red blood cell transfusion practices in aneurysmal subarachnoid hemorrhage: results of a multicenter cohort study
}

Shane W. English ${ }^{1,2^{*}}$ (D, Michaël Chassé ${ }^{3}$, Alexis F. Turgeon ${ }^{4}$, François Lauzier ${ }^{4,5}$, Donald Griesdale ${ }^{6}$, Allan Garland ${ }^{7}$, Dean Fergusson ${ }^{2}$, Ryan Zarychanski ${ }^{7}$, Carl van Walraven ${ }^{8}$, Kaitlyn Montroy ${ }^{2}$, Jennifer Ziegler ${ }^{7}$,

Raphael Dupont-Chouinard ${ }^{4}$, Raphaëlle Carignan ${ }^{4}$, Andy Dhaliwal ${ }^{9}$, Ranjeeta Mallick ${ }^{2}$, John Sinclair ${ }^{10}$,

Amélie Boutin ${ }^{11}$, Giuseppe Pagliarello ${ }^{12}$, Alan Tinmouth², Lauralyn Mclntyre ${ }^{1,2}$ and on behalf of the Canadian

Critical Care Trials Group

\begin{abstract}
Background: Whether a restrictive strategy for red blood cell (RBC) transfusion is applied to patients with aneurysmal subarachnoid hemorrhage (aSAH) is unclear. To inform the design and conduct of a future clinical trial, we sought to describe transfusion practices, hemoglobin $(\mathrm{Hb})$ triggers, and predictors of RBC transfusion in patients with aSAH.

Methods: This is a retrospective cohort study of all consecutively admitted adult patients with aSAH at four tertiary care centers from January 1, 2012, to December 31, 2013. Patients were identified from hospital administrative discharge records and existing local aSAH databases. Data collection by trained abstractors included demographic data, aSAH characteristics, $\mathrm{Hb}$ and transfusion data, other major aSAH cointerventions, and outcomes using a pretested case report form with standardized procedures. Descriptive statistics were used to summarize data, and regression models were used to identify associations between anemia, transfusion, and other relevant predictors and outcome.

Results: A total of 527 patients met inclusion eligibility. Mean ( \pm SD) age was $57 \pm 13$ years, and 357 patients (67.7\%) were female. The median modified Fisher grade was 4 (IQR 3-4). Mean nadir Hb was $98 \pm 20 \mathrm{~g} / \mathrm{L}$ and occurred on median admission day 4 (IQR 2-11). RBC transfusion occurred in 100 patients (19.0\%). Transfusion rates varied across centers (12.1-27.4\%, $p=0.02$ ). Patients received a median of 1 RBC unit (IQR 1-2) per transfusion episode and a median total of 2 units (IQR 1-4). Median pretransfusion $\mathrm{Hb}$ for first transfusion was $79 \mathrm{~g} / \mathrm{L}$ (IQR 74-93) and did not vary substantially across centers (78-82 $\mathrm{g} / \mathrm{L}, p=0.37)$. Of patients with nadir $\mathrm{Hb}<80 \mathrm{~g} / \mathrm{L}, 66.3 \%$ received a transfusion compared with $2.0 \%$ with $\mathrm{Hb}$ nadir $\geq 100 \mathrm{~g} / \mathrm{L}$ ( $p<0.0001$ ). Predictors of transfusion were history of oral anticoagulant use, anterior circulation aneurysm, neurosurgical clipping, and lower Hb. Controlling for numerous potential confounders, transfusion was not independently associated with poor outcome.

Conclusions: We observed that moderate anemia remains very common early in admission following SAH. Only one-fifth of patients with SAH received RBC transfusions, mostly in cases of significant anemia ( $\mathrm{Hb}<80 \mathrm{~g} / \mathrm{L})$, and this did not appear to be associated with outcome.
\end{abstract}

Keywords: Subarachnoid hemorrhage, Cerebral aneurysm, Anemia, Red blood cell transfusion, Cohort study

\footnotetext{
* Correspondence: senglish@ohri.ca

'Department of Medicine (Critical Care), The Ottawa Hospital, Civic Campus

Room F202, 1053 Carling Avenue, Ottawa, ON K1Y 4E9, Canada

${ }^{2}$ Clinical Epidemiology Program (Centre for Transfusion Research), Ottawa

Hospital Research Institute, Ottawa, ON, Canada

Full list of author information is available at the end of the article
}

(c) The Author(s). 2018 Open Access This article is distributed under the terms of the Creative Commons Attribution 4.0 International License (http://creativecommons.org/licenses/by/4.0/), which permits unrestricted use, distribution, and reproduction in any medium, provided you give appropriate credit to the original author(s) and the source, provide a link to the Creative Commons license, and indicate if changes were made. The Creative Commons Public Domain Dedication waiver (http://creativecommons.org/publicdomain/zero/1.0/) applies to the data made available in this article, unless otherwise stated. 


\section{Background}

Most atraumatic subarachnoid hemorrhages are caused by a ruptured cerebral artery aneurysm (aneurysmal subarachnoid hemorrhage [aSAH]). Patients who survive the primary event are at high risk of complications, including delayed cerebral ischemia (DCI) such as with vasospasm, which may result in further neurologic deficits and increased likelihood of death [1]. Initial management focuses on patient stabilization and support; securing of the aneurysm; and monitoring for, preventing, and treating potential complications [2, 3]. Medical complications, including anemia, are common and affect up to $50 \%$ of patients with aSAH [4]. Among them, both anemia and transfusion of red blood cells (RBC) have been associated with complications and poor outcomes [4]. Anemic patients with aSAH are not only more likely to receive RBC transfusions but also at an increased risk of ischemic complications [4]. Those who receive RBC transfusions have been shown to have less favorable hospital outcomes, including severe disability [5].

Preclinical studies in brain injury suggest that RBC transfusion to treat anemia improves oxygen delivery [6]. Only one small trial $(N=44)$ has compared two transfusion targets $(100 \mathrm{~g} / \mathrm{L}$ and $115 \mathrm{~g} / \mathrm{L})$ in aSAH, but it was underpowered to examine clinically important outcomes [7]. Another small mixed brain injury population trial $(N=102)$ compared a hemoglobin $(\mathrm{Hb})$ target with a transcranial oxygenation target, but it, too, was underpowered to examine clinically important outcomes [8]. Despite this absence of evidence, current aSAH management guidelines recommend considering $\mathrm{RBC}$ transfusion in anemic patients at risk for cerebral ischemia, but they do not suggest specific transfusion thresholds to guide clinicians [1, 3]. These recommendations are in contrast with current stated aSAH management practice derived from surveys [9] and evidence from clinical trials in other critically ill adult and pediatric populations, which support a more restrictive RBC transfusion approach $[10,11]$.

Canadian epidemiologic data on aSAH is sparse and more than 20 years old [12]. These data are limited to characterizing hospitalizations and case fatality rates with no published data on transfusion practices, which have changed significantly in critically ill patients over the last decade. In collaboration with the Canadian Critical Care Trials Group, we conducted a retrospective, multicenter cohort study of consecutive patients with aSAH to better understand current RBC transfusion practices.

\section{Methods}

\section{Study design and objectives}

We conducted a multicenter retrospective observational study of patients with aSAH admitted to one of four Canadian academic tertiary care hospitals in four different provinces. This study was approved by the local research ethics board of each participating center, which waived the need for informed consent.

Our a priori primary objective was to describe $\mathrm{RBC}$ transfusion practices, including the distribution of $\mathrm{Hb}$ values at which patients are transfused, the proportion of patients transfused, the median number of RBC transfusions per patient, the predictors of anemia and transfusion, and practice variations between participating centers. Our secondary objective was to examine the association of $\mathrm{RBC}$ transfusion and clinical outcome.

\section{Patient selection}

We included all consecutive admissions for aSAH between January 1, 2012, and December 31, 2013. We identified potentially eligible patients by screening two sources: (1) hospital discharge abstracts, including all discharge abstracts that listed the diagnosis of primary SAH using International Classification of Diseases, Tenth Revision (ICD-10), codes (I60.0 to I60.9), and, where available, (2) local database or patient repositories, including all patients with a diagnosis of aSAH obtained from an existing local hospital, intensive care unit (ICU), or neurosurgical database. The local database had to include consecutive cases and be searchable by principal diagnoses that were not ICD code-generated.

Each patient underwent chart review by a trained data abstractor. For final inclusion in the cohort, patients had to be $\geq 18$ years of age and to have sustained an aSAH. The diagnosis of aSAH required both evidence of $\mathrm{SAH}$ (by at least one of the following: blood in subarachnoid space as demonstrated by neuroimaging [e.g., computed tomography $\{\mathrm{CT}\}$, magnetic resonance imaging, lumbar puncture demonstrating xanthochromia and/or $>5 \times 10^{6} \mathrm{RBCs} / \mathrm{L}$, or blood in subarachnoid space as observed at postmortem autopsy report) and (2) evidence of aneurysm rupture as the cause (by at least one of the following: aneurysm observed on angiography, aneurysm demonstrated on neuroimaging report [computed tomographic angiography or magnetic resonance angiography], or aneurysm observed on postmortem examination report). No exclusion criteria were used, because we wanted to describe all adult patients with true aSAH as established by the inclusion criteria. Similar criteria have been used in previous cohort studies examining anemia and RBC transfusion in aSAH $[5,13]$.

\section{Patient management}

All four study centers are academic tertiary care referral hospitals with complete neurosurgical, neurointerventional, and intensive care services. Management of patients with aSAH was in accordance with local practice and procedures and the most recent aSAH management guidelines [3]. Specifically, acute care goals included early treatment of hydrocephalus and securing of ruptured aneurysm, as well as traditional management of intracranial hypertension with 
goal-directed osmotic therapy. All sites fostered early detection of DCI with close clinical observation with or without serial surveillance imaging (e.g., transcranial Doppler). Medical complications of aSAH, including cardiac dysfunction, electrolyte abnormalities, and temperature dysregulation, were managed according to local practice and in accordance with accepted standards.

At each site, acute care management of patients with aSAH occurred in either a level 3 ICU for mechanically ventilated and/or unstable patients or in a level 2 high-acuity unit until such time that the aneurysm was secured, the patient was off all life supports and vasoactive medications, and in the absence of DCI. During the study period, no participating center had a specific RBC transfusion protocol for managing aSAH, nor did any of them have specific transfusion guidelines, and the decision to initiate as well as the timing of RBC transfusion was at the discretion of the treating team.

\section{Data collection}

Data collection was completed by trained data abstractors using a previously prepared and piloted case report form and a standardized operations manual tested for completeness, clarity, and ease of use. We used multiple sources, including electronic and paper medical records as well as laboratory and imaging reports. An ICU day was considered any amount of time in a single calendar day admitted to a level 2 or 3 unit (Additional file 1: Supplemental Material). SAH severity was captured with Hunt and Hess grade [14], World Federation of Neurological Surgeons grade [15], and/or the modified Fisher scale [16]. When not explicitly reported, modified Fisher scale grade was calculated using the first available CT scan.

The date and time of each RBC transfusion administered was recorded. Multiple units of RBCs transfused on the same calendar day were considered to be part of a single transfusion episode, unless separate transfusions occurred intraoperatively (this was considered a separate transfusion episode). A pretransfusion $\mathrm{Hb}$ (defined as the most recent $\mathrm{Hb}$ [within $48 \mathrm{~h}$ ] drawn prior to the initiation of RBC transfusion) was captured for each transfusion episode. In the $6 \mathrm{~h}$ preceding an RBC transfusion, we identified episodes of active bleeding (defined as more than $250 \mathrm{ml}$ of blood loss in $1 \mathrm{~h}$ or active blood loss associated with hemodynamic instability). We captured admission $\mathrm{Hb}$, daily nadir $\mathrm{Hb}$ values for the first 21 days of admission, and hospitalization and ICU stay nadir $\mathrm{Hb}$. We defined anemia as a $\mathrm{Hb}$ value less than or equal to $100 \mathrm{~g} / \mathrm{L}$ because this value has clinical significance and represents an important threshold in multiple previously published transfusion trials [11, 17-19]. Diagnostic criteria for vasospasm and cerebral infarction were established a priori (Additional file 1: Supplemental Material).
We recorded vital status at discharge, discharge destination (home, other hospital, rehabilitation, long-term care/ nursing home, or other), and functional status at discharge applying the modified Rankin Scale (mRS) criteria (from 0 to 6) (Additional file 1: Supplemental Material). Functional status was ascertained using available documentation, including physiotherapy and occupational therapy discharge notes and rehabilitation assessments. We dichotomized status at discharge to good (mRS 0-3) or poor (mRS 4-6) outcome.

\section{Statistical analyses}

Descriptive statistics were used to summarize the study data. Continuous variables are presented as mean with SD or median with IQR, depending on their distribution. Frequency and proportion estimates are presented as point estimates with $95 \%$ CIs. We used the chi-square or Fisher's exact test, as appropriate, to examine differences in transfusion rates among different trigger thresholds. Predictors of anemia, RBC transfusion, and poor neurologic functional outcome were tested using a random effects generalized linear model to account for clustering at the center level. Potential predictor variables for each model were set a priori and included variables identified previously in the literature and those with clinical significance. For anemia, these included admission $\mathrm{Hb}$, age, gender, history of oral anticoagulant, modified Fisher grade, aneurysm size, method of securing the aneurysm (clip vs coil), and presence of vasospasm (prior to onset of anemia). For RBC transfusion, predictors considered included age, gender, history of oral anticoagulant, modified Fisher grade, location of aneurysm (anterior vs posterior circulation), method of securing the aneurysm (clip vs coil), admission $\mathrm{Hb}$, presence of anemia, and vasospasm or cerebral infarction (prior to the first RBC transfusion). Owing to the clinical correlation between the latter two, only vasospasm was considered in the final model. Finally, predictors of poor outcome entered in the model included all of the previously mentioned variables and other preexisting comorbidities, presenting Glasgow Coma Scale (GCS) score, need for mechanical ventilation, hospital length of stay, need for ICU admission, need for tracheostomy, or need for percutaneous gastrostomy tube. Similarly, given the clinical correlation between the need for mechanical ventilation, need for ICU admission, and need for tracheostomy, we did not include need for ICU admission in the final model, because it was least significant in univariate analysis. Cerebral infarction was included (instead of vasospasm) owing to its significant correlation during univariate analysis. We examined for multicollinearity among predictors. Statistical interaction between certain variables was considered and included in the model only if statistically significant. Statistical significance was considered as a $p$ value $<0.05$. All analyses were 
completed using SAS 9.3 software (SAS Institute, Cary, NC, USA).

\section{Results}

Of the 886 screened patients, 42 had no SAH, and 317 had SAH resulting from causes other than aneurysm rupture, leaving a cohort of 527 patients. Baseline and disease-specific characteristics, cointerventions, and disease-related complications are presented in Table 1.

\section{Anemia}

Anemia at presentation was found in 29 patients (5.5\%). Among the other 498 patients, the hospitalization incidence of acquired anemia was 52.0\% (47.6-56.4\%). The overall prevalence of anemia within the first 21 days

Table 1 Patient characteristics, interventions, and complications

\begin{tabular}{|c|c|}
\hline & $\begin{array}{l}\text { Data } \\
(N=527)\end{array}$ \\
\hline \multicolumn{2}{|l|}{ Characteristics } \\
\hline Age, $y r$, mean $\pm S D$ & $57 \pm 13$ \\
\hline Female, no. (\%) & $357(67.7)$ \\
\hline \multicolumn{2}{|l|}{ Comorbidities, no. (\%) } \\
\hline Hypertension & $233(44.2)$ \\
\hline Heart disease & $41(7.8)$ \\
\hline Active tobacco smoker & $185(35.1)$ \\
\hline \multicolumn{2}{|l|}{ Home medications, no. (\%) } \\
\hline Antiplatelet & $67(12.7)$ \\
\hline Oral anticoagulant & $20(3.8)$ \\
\hline Statin & $100(19.0)$ \\
\hline \multicolumn{2}{|l|}{ aSAH characteristics } \\
\hline Presenting GCS, mean \pm SD & $11 \pm 5$ \\
\hline Modified Fisher scale score, median (IQR) & $4(3-4)$ \\
\hline \multicolumn{2}{|l|}{ Aneurysm } \\
\hline Size, $\mathrm{mm}$, mean $\pm \mathrm{SD}$ & $6.9 \pm 4.3$ \\
\hline Posterior circulation, no. (\%) & $182(34.5)$ \\
\hline Anterior circulation, no. (\%) & $327(62)$ \\
\hline \multicolumn{2}{|l|}{ Interventions and cointerventions, no. (\%) } \\
\hline Surgical clipping & 209 (39.7) \\
\hline Endovascular coiling & $275(52.5)$ \\
\hline Postadmission day aneurysm secured, median (IQR) ${ }^{\mathrm{a}}$ & $0(0-1)$ \\
\hline EVD & $236(44.8)$ \\
\hline RBC transfusion & $100(19.0)$ \\
\hline Need for mechanical ventilation & $216(49.8)$ \\
\hline \multicolumn{2}{|l|}{ Complications, no. (\%) } \\
\hline Vasospasm & $142(26.9)$ \\
\hline New ischemic neurologic lesions & $104(19.7)$ \\
\hline
\end{tabular}

Abbreviations: aSAH Aneurysmal subarachnoid hemorrhage, EVD Externalized ventricular drain, GCS Glasgow Coma Scale, RBC Red blood cells

aEleven dates missing of admission was 51.8\% (95\% CI 47.5-56.1\%). The mean hospitalization nadir $\mathrm{Hb}$ was $98.0 \pm 19.5 \mathrm{~g} / \mathrm{L}$ and occurred on median admission day 4 (IQR 2-11). The proportion of anemic patients varied across centers $(p=0.005)$ (Additional file 1: Figure S1). Female sex, history of oral anticoagulant use, modified Fisher grade 3 or 4 , admission $\mathrm{Hb}$, and aneurysm secured by neurosurgical clipping were independent predictors of anemia (see Table 2).

\section{Primary outcome: RBC transfusion practices}

Overall, 100 patients (19.0\%, 95\% CI 15.6-22.3\%) underwent transfusion of at least 1 unit of packed red blood cells (PRBCs). A median of 1 unit of PRBCs (IQR 1-2) per transfusion episode was received, and a median of 2 units of PRBCs (IQR 1-3) was received during the hospitalization. The median pretransfusion $\mathrm{Hb}$ of the first transfusion was $79 \mathrm{~g} / \mathrm{L}$ (IQR 74-93), and the median was $80 \mathrm{~g} / \mathrm{L}$ (IQR 72-86) for all transfusions. A total of 35 patients $(6.6 \%)$ had an intraoperative transfusion, and 24 patients (4.6\%) received $\geq 1$ unit of PRBCs within $6 \mathrm{~h}$ of active bleeding.

We grouped patients by their $\mathrm{Hb}$ nadir (in nontransfused patients) and pretransfusion $\mathrm{Hb}$ of first transfusion (in transfused patients) in $\mathrm{Hb}$ increments of $10 \mathrm{~g} / \mathrm{L}$. RBC transfusion rates were highest in those patients with $\mathrm{a} \mathrm{Hb}$ $<80 \mathrm{~g} / \mathrm{L}(p<0.0001)$ (Fig. 1). Among patients with a nadir $\mathrm{Hb}$ of $100 \mathrm{~g} / \mathrm{L}$ or higher, only $7.0 \%$ of patients received an $\mathrm{RBC}$ transfusion.

Transfusion rates varied from $12.5 \%$ to $27.4 \%$ across participating sites $(p=0.016)$ (Additional file 1: Figure S2). However, median pretransfusion $\mathrm{Hb}$ did not vary significantly between sites, ranging from 78 to $82 \mathrm{~g} / \mathrm{L}(p=0.37)$ (Fig. 2).

\section{Predictors of RBC transfusion}

Univariate predictors of at least $1 \mathrm{RBC}$ transfusion included history of home anticoagulant use, lower admission $\mathrm{Hb}$, ruptured aneurysm in the anterior cerebral circulation, secured aneurysm by neurosurgical clipping, and anemia (Table 3). In our regression model, only lower admission $\mathrm{Hb}$, ruptured aneurysm secured by neurosurgical clipping, and anemia remained independent risk factors for transfusion. Among patients with vasospasm, the only predictor of transfusion was moderate anemia (OR 9.59, 95\% CI 2.7533.48, $p=0.0004$ ).

We stratified patients on the basis of their nadir $\mathrm{Hb}$ to examine differences in transfusion predictors. Among the most severely anemic patients $(\mathrm{Hb}<80 \mathrm{~g} / \mathrm{L}, n=98), 66.3 \%$ (65 patients; $95 \%$ CI $57.0-75.7 \%$ ) of patients received a transfusion with no identifiable significant predictors in our model (Table 4). In the moderate anemia group $(80 \leq$ $\mathrm{Hb}<100 \mathrm{~g} / \mathrm{L}, n=175$ ), $17.1 \%$ (30 patients; 95\% CI 11.6$22.7 \%)$ received a transfusion. Independent predictors of transfusion in this group were increasing age (per 10-year 
Table 2 Predictors of anemia ( $\mathrm{Hb} \leq 100 \mathrm{~g} / \mathrm{L})$ during admission for subarachnoid hemorrhage, clustered by center

\begin{tabular}{|c|c|c|c|c|c|c|c|}
\hline \multicolumn{4}{|l|}{ Univariate analysis } & \multicolumn{4}{|l|}{ Multivariable model ( $n=437 ; 238$ events) } \\
\hline Variable & OR & $95 \% \mathrm{Cl}$ & $p$ Value & Variable & OR & $95 \% \mathrm{Cl}$ & $p$ Value \\
\hline Age (increase by $10 \mathrm{yr}$ ) & 1.02 & $0.97-1.08$ & 0.472 & Age (increase by 10 years) & 0.99 & $0.91-1.09$ & 0.913 \\
\hline Sex (female vs other) & 2.82 & $1.76-4.50$ & $<0.0001$ & Sex (female vs other) & 1.91 & $1.08-3.40$ & 0.027 \\
\hline $\mathrm{Hx}$ of oral $\mathrm{AC}$ use & 6.17 & $2.79-14.97$ & $<0.0001$ & $\mathrm{Hx}$ of oral $\mathrm{AC}$ use & 5.98 & $2.11-16.95$ & 0.001 \\
\hline $\begin{array}{l}\text { Admission hemoglobin } \\
\text { (increase by } 10 \mathrm{~g} / \mathrm{L} \text { ) }\end{array}$ & 0.35 & $0.32-0.39$ & $<0.0001$ & Admission hemoglobin (increase by $10 \mathrm{~g} / \mathrm{L}$ ) & 0.55 & $0.43-0.71$ & $<0.0001$ \\
\hline Modified Fisher grade $3-4$ vs $0-2^{a}$ & 1.42 & $0.98-2.08$ & 0.067 & Modified Fisher grade $3-4$ vs $0-2^{a}$ & 1.96 & $1.07-3.57$ & 0.028 \\
\hline Anterior circulation (vs posterior) & 0.98 & $0.65-1.48$ & 0.929 & Anterior circulation (vs posterior) & 0.58 & $0.30-1.13$ & 0.107 \\
\hline Aneurysm size (increase by $1 \mathrm{~mm}$ ) & 1.03 & $1.02-1.05$ & $<0.0001$ & Aneurysm size (increase by $1 \mathrm{~mm}$ ) & 1.03 & $0.98-1.07$ & 0.226 \\
\hline Clip (vs other) & 3.19 & $2.09-4.85$ & $<0.0001$ & Clip (vs other) & 4.62 & $2.46-8.69$ & $<0.0001$ \\
\hline Vasospasm (preanemia) & 0.78 & $0.52-1.17$ & 0.223 & Vasospasm (preanemia) & 1.49 & $0.79-2.80$ & 0.214 \\
\hline
\end{tabular}

Abbreviations: AC Anticoagulant, antiplt Antiplatelet, $H b$ Hemoglobin, Hx History, RBCTx Red blood cell transfusion, SAH Subarachnoid hemorrhage

${ }^{\mathrm{a}}$ Dichotomized as high (3-4) vs low (0-2) grade

increase OR 1.18, 95\% CI 1.10-1.26), male sex (OR 1.42, 95\% CI 1.03-1.96), and neurosurgical clipping of the aneurysm (OR 4.60, 95\% CI 1.89-11.17). Of the 254 patients in the nonanemic group (nadir $\mathrm{Hb} \geq 100 \mathrm{~g} / \mathrm{L}$ ), 5 patients $(2.0 \%, 95 \%$ CI $0.6-4.5 \%)$ received a transfusion. There were insufficient events to identify independent predictors of transfusion in this group.

\section{RBC transfusion association with outcome}

Neurologic functional outcome at discharge was missing for 66 patients (12.5\%). By hospital discharge, 93 (20.2\%) patients had died and $220(47.7 \%)$ had a poor neurologic outcome (mRS 4-6). Although both anemia $(\mathrm{Hb}<100 \mathrm{~g} / \mathrm{L})$ and $\mathrm{RBC}$ transfusion were predictors of poor outcome (ORs 2.44 and 3.72, 95\% CIs 1.67-3.57 and 2.23-6.19, respectively), neither of them was a significant independent predictor when controlling for these and other factors that are likely to affect outcome (Table 5). Independent predictors of poor neurologic outcome included increasing age; history of hypertension, stroke, or ever smoking; home oral anticoagulant use, high-grade modified Fisher grade; anterior circulation aneurysm; poor GCS at presentation; need for mechanical ventilation; and need for percutaneous gastrostomy tube (Table 4).

\section{Discussion}

In this multicenter retrospective review of patients with aSAH, we found that although moderate anemia incidence remains very high (51.8\%), RBC transfusion is uncommon (19.0\%). Significant RBC transfusion rates were only observed with severe anemia $(\mathrm{Hb} \leq 80 \mathrm{~g} / \mathrm{L})$, suggesting a "restrictive" RBC transfusion practice among the hospitals

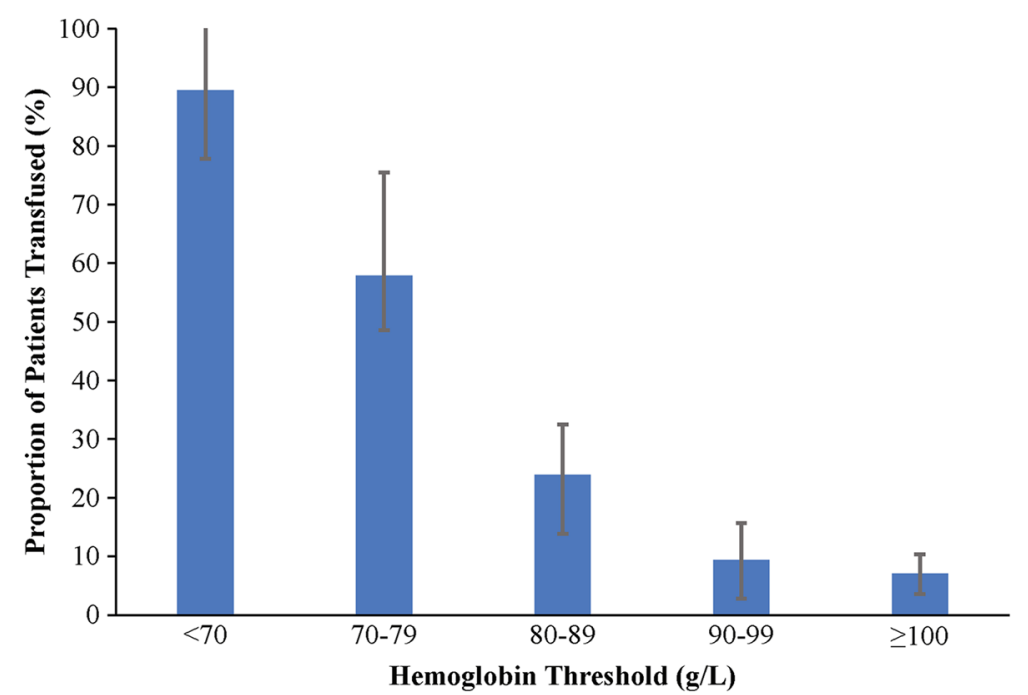

Fig. 1 Red blood cell transfusion rates across hemoglobin thresholds. Proportion of patients transfused according to hemoglobin threshold. Error bar depicts proportion $95 \% \mathrm{Cl}$ 


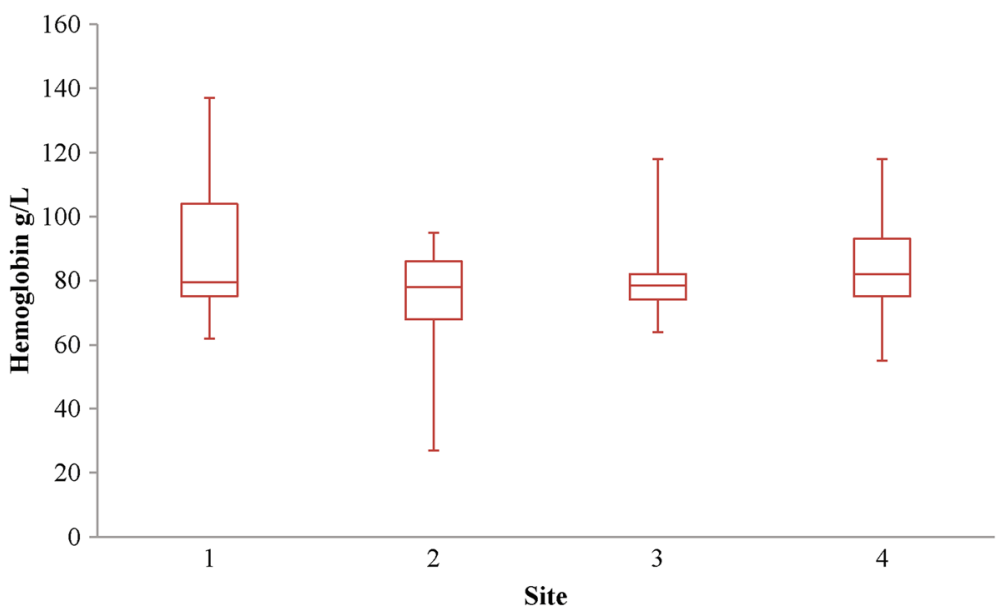

Fig. 2 Red blood cell transfusion threshold site variation. Whisker box plot of pretransfusion hemoglobin according to site. The center line in the box represents the median, and the outside lines of the box represent the first and third quartiles. The lines extending from the boxes demonstrate the minimum and maximum values

in the study. Although the proportion of patients transfused differed across participating sites, the median pretransfusion $\mathrm{Hb}$ did not differ, ranging from 78 to $82 \mathrm{~g} / \mathrm{L}$. In this large and robust dataset, controlling for other clinical factors that may influence outcome, RBC transfusion was not correlated with negative outcomes. Further, although our data are not able to demonstrate if RBC transfusion is in fact helpful in the improvement of neurologic outcome, in the current cohort, it is a marker of disease severity.

Our findings are important and add significantly to the aSAH and transfusion literature for several reasons. First, this is the first multi-institutional study examining RBC transfusion practice in this patient population. Second, we have described independent predictors of RBC transfusion using a robust dataset. Further, we have attempted to describe how these factors may change depending on the level of $\mathrm{Hb}$ of a given patient. Last, we have demonstrated with a large, multicenter dataset populated with a large number of variables that, when controlling for other important factors, $\mathrm{RBC}$ transfusion does not appear to be a predictor of poor neurologic functional outcome at hospital discharge, but we cannot conclude that it is either harmful or helpful in this population.

The common occurrence of anemia following aSAH has been previously described $[4,5]$. Despite changes in common management strategies of patients with aSAH since these earlier descriptions, including a movement away from hypervolemia and hemodilution (two of the so-called triple- $\mathrm{H}$ therapies) in favor of hyperdynamic therapy for DCI management [20], our findings suggest that this has had little impact on anemia incidence. Nonetheless, our findings also suggest that RBC transfusion is uncommon relative to the incidence of anemia and

Table 3 Predictors of one or more red blood cell transfusions during admission for subarachnoid hemorrhage, clustered by center

\begin{tabular}{|c|c|c|c|c|c|c|c|}
\hline \multicolumn{4}{|l|}{ Univariate analysis } & \multicolumn{4}{|l|}{ Multivariable model ( $n=463 ; 95$ events) } \\
\hline Variable & OR & $95 \% \mathrm{Cl}$ & $p$ Value & Variable & OR & $95 \% \mathrm{Cl}$ & $p$ Value \\
\hline Age (increase by 10 years) & 1.07 & $0.90-1.28$ & 0.458 & Age (increase by 10 years) & 1.06 & $0.78-1.45$ & 0.711 \\
\hline Sex (male vs other) & 0.45 & $0.19-1.10$ & 0.080 & Sex (male vs other) & 0.84 & $0.45-1.57$ & 0.593 \\
\hline $\mathrm{Hx}$ of oral $\mathrm{AC}$ use & 1.93 & $1.01-3.68$ & 0.046 & Hx of Oral AC use & 1.00 & $0.60-1.67$ & 0.993 \\
\hline Admission $\mathrm{Hb}$ (increase by $10 \mathrm{~g} / \mathrm{L}$ ) & 0.40 & $0.39-0.41$ & $<0.0001$ & Admission $\mathrm{Hb}$ (increase by $10 \mathrm{~g} / \mathrm{L}$ ) & 0.81 & $0.69-0.96$ & 0.013 \\
\hline Modified Fisher grade $3-4$ vs $0-2^{a}$ & 1.02 & $0.90-1.15$ & 0.765 & Modified Fisher Grade 3-4 vs 0-2a & 1.02 & $0.77-1.36$ & 0.876 \\
\hline Anterior circulation (vs posterior) & 1.46 & $1.17-1.83$ & 0.001 & Anterior circulation (vs Posterior) & 1.18 & $0.90-1.55$ & 0.231 \\
\hline Clip (vs other) & 4.39 & $3.25-5.92$ & $<0.0001$ & Clip (vs other) & 2.44 & $1.21-4.94$ & 0.013 \\
\hline Anemia $(\mathrm{Hb} \leq 100 \mathrm{~g} / \mathrm{L})$ & 28.17 & $11.06-71.75$ & $<0.0001$ & Anemia $(\mathrm{Hb} \leq 100 \mathrm{~g} / \mathrm{L})$ & 17.38 & $5.11-59.13$ & $<0.0001$ \\
\hline Vasospasm (pre-RBCTx) & 1.62 & $0.91-2.88$ & 0.100 & Vasospasm (pre-RBCTx) & 1.11 & $0.40-3.09$ & 0.845 \\
\hline Cerebral infarct (pre-RBCTx) & 1.08 & $0.96-1.23$ & 0.206 & & & & \\
\hline
\end{tabular}


Table 4 Predictors (multivariable model) of red blood cell transfusion, stratified by nadir hemoglobin

\begin{tabular}{|c|c|c|c|c|c|c|}
\hline \multirow[t]{2}{*}{ Variable } & \multicolumn{3}{|c|}{$\begin{array}{l}\mathrm{Hb}<80 \mathrm{~g} / \mathrm{L} \\
(n=83 ; 61 \text { RBCTx events) }\end{array}$} & \multicolumn{3}{|c|}{$\begin{array}{l}80 \leq \mathrm{Hb}<100 \mathrm{~g} / \mathrm{L} \\
(n=168 ; 32 \mathrm{RBCTx} \text { events) }\end{array}$} \\
\hline & $\mathrm{OR}$ & $95 \% \mathrm{Cl}$ & $p$ Value & $\mathrm{OR}$ & $95 \% \mathrm{Cl}$ & $p$ Value \\
\hline Age (increase by 10 years) & 1.03 & $0.82-1.29$ & 0.801 & 1.18 & $1.10-1.26$ & $<0.0001$ \\
\hline Male sex (vs other) & 0.48 & $0.13-1.87$ & 0.293 & 1.42 & $1.03-1.96$ & 0.031 \\
\hline Fisher grade 3-4 (vs 0-2) & 1.29 & $0.76-2.18$ & 0.347 & 0.64 & $0.29-1.42$ & 0.268 \\
\hline Anterior circulation (vs posterior) & 1.77 & $0.65-4.79$ & 0.262 & 0.85 & $0.60-1.22$ & 0.385 \\
\hline Clip (vs other) & 1.00 & $0.16-6.18$ & 1.000 & 4.60 & $1.89-11.17$ & 0.001 \\
\hline Vasospasm (pre-RBCTx) & 0.81 & $0.23-2.91$ & 0.751 & 1.57 & $0.68-3.62$ & 0.294 \\
\hline
\end{tabular}

Hb Hemoglobin, RBCTx Red blood cell transfusion

is largely restricted to those with severe anemia (median $\mathrm{Hb} \leq 80 \mathrm{~g} / \mathrm{L}$ ). This "restrictive $\mathrm{RBC}$ transfusion" practice is in keeping with a stated practice from a 2010 North American survey [21]. Our observed practice is vastly different from the two transfusion triggers $(100 \mathrm{~g} / \mathrm{L}$ vs $115 \mathrm{~g} / \mathrm{L}$ ) employed in the only randomized controlled trial examining RBC transfusion thresholds in patients with $\mathrm{aSAH}$ and from the current aSAH management guidelines, which include a recommendation to consider RBC transfusion in anemic patients at risk for cerebral ischemia [3].
Four prior studies $[5,22-24]$ and an abstract publication [25] report adjusted analyses of the effect of RBC transfusion on poor outcome, using a variety of control variables. Additionally, three prior studies [5, 26, 27] (and two potentially related abstracts $[28,29]$ ) report adjusted analyses of effect of RBC transfusion on mortality. Two demonstrated a statistically significant association:

1. RBC transfusion increased the odds of death by threefold (OR 3.16, 95\% CI 1.02-9.69) when controlling for nadir $\mathrm{Hb}$ (and its interaction with $\mathrm{RBC}$ transfusion) in an $\mathrm{RBC}$ transfusion propensity score

Table 5 Predictors of poor outcome ${ }^{a}$, clustered by center

\begin{tabular}{|c|c|c|c|c|c|c|c|}
\hline \multicolumn{4}{|l|}{ Univariate analysis } & \multicolumn{4}{|c|}{ Multivariable model ( $n=404 ; 199$ events) } \\
\hline Variable & OR & $95 \% \mathrm{Cl}$ & $p$ Value & Variable & OR & $95 \% \mathrm{Cl}$ & $p$ Value \\
\hline Age (increase by 10 years) & 1.65 & $1.28-2.12$ & 0.0001 & Age (increase by 10 year) & 1.58 & $1.30-1.93$ & $<0.0001$ \\
\hline Sex (male vs other) & 0.92 & $0.71-1.20$ & 0.548 & Sex (male vs other) & 0.96 & $0.35-2.63$ & 0.936 \\
\hline History of hypertension & 2.06 & $1.56-2.72$ & $<0.0001$ & History of Hypertension & 1.47 & $1.06-2.03$ & 0.022 \\
\hline History of ischemic stroke & 9.22 & $3.81-22.35$ & $<0.0001$ & History of Ischemic stroke & 7.85 & $2.29-26.92$ & 0.001 \\
\hline History of heart disease & 2.99 & $1.40-6.41$ & 0.005 & History of Heart disease & 1.02 & $0.33-3.12$ & 0.976 \\
\hline Smoking history & 0.54 & $0.38-0.78$ & 0.0009 & Smoking history & 0.58 & $0.34-0.99$ & 0.047 \\
\hline Home oral anticoagulant & 8.44 & $1.22-58.54$ & 0.031 & Home Oral anticoagulant & 5.38 & $1.48-19.64$ & 0.011 \\
\hline Fisher grade $3-4$ vs $0-2$ & 2.83 & $2.31-3.45$ & $<0.0001$ & Fisher Grade 3-4 vs 0-2 & 1.60 & $1.45-1.77$ & $<0.0001$ \\
\hline Anterior circulation (vs posterior) & 1.17 & $1.00-1.37$ & 0.056 & Anterior circulation (vs Posterior) & 1.54 & $1.10-2.14$ & 0.011 \\
\hline GCS (for each increase by 1 ) & 0.82 & $0.81-0.84$ & $<0.0001$ & GCS (for each increase by 1 ) & 0.95 & $0.90-1.00$ & 0.045 \\
\hline Need for mechanical ventilation & 9.58 & $6.89-13.31$ & $<0.0001$ & Need for Mechanical Ventilation & 4.94 & $3.14-7.78$ & $<0.0001$ \\
\hline Clip (vs other) & 0.86 & $0.48-1.54$ & 0.602 & Clip (vs other) & 0.58 & $0.24-1.42$ & 0.233 \\
\hline $\mathrm{RBCTx}$ & 3.72 & $2.23-6.19$ & $<0.0001$ & $\mathrm{RBCTx}$ & 1.50 & $0.83-2.71$ & 0.175 \\
\hline Anemia $(\mathrm{Hb} \leq 100 \mathrm{~g} / \mathrm{L})$ & 2.44 & $1.67-3.57$ & $<0.0001$ & Anemia $(\mathrm{Hb} \leq 100 \mathrm{~g} / \mathrm{L})$ & 1.06 & $0.57-1.97$ & 0.860 \\
\hline Vasospasm & 1.35 & $0.84-2.18$ & 0.217 & Cerebral Infarct & 1.78 & $0.75-4.21$ & 0.188 \\
\hline Cerebral infarct & 2.83 & $1.73-4.65$ & $<0.0001$ & Hospital length of stay & 1.00 & $0.99-1.00$ & 0.456 \\
\hline Hospital length of stay & 1.01 & $1.00-1.02$ & 0.016 & Need for tracheostomy & 1.97 & $0.45-8.57$ & 0.365 \\
\hline Need for ICU/IMCU admission & 1.38 & $0.48-3.92$ & 0.549 & Need for PEG tube & 8.62 & $1.12-66.56$ & 0.039 \\
\hline Need for tracheostomy & 7.96 & $2.89-21.89$ & $<0.0001$ & & & & \\
\hline Need for PEG tube & 25.22 & $6.28-101.37$ & $<0.0001$ & & & & \\
\hline
\end{tabular}

Abbreviations: GCS Glasgow Coma Scale, Hb Hemoglobin, ICU Intensive care unit, IMCU Intermediate care unit, PEG Percutaneous gastrostomy tube, RBCTx Red blood cell transfusion

a 67 missing 
analysis of predicted mortality using a cohort from two hospitals [26]

2. A fourfold increase in odds of death or poor neurologic outcome was seen with RBC transfusion (OR 4.3, 95\% CI 1.9-9.3) in a single-center cohort when controlling for age, SAH severity, and anemia [5].

The differences found in our study may be attributable to its larger, more current sample, higher event rates, and multicenter contribution to the cohort, distinguishing it from all of these previous studies.

The strengths of this study lie in the rigorous methodology employed to minimize some of the biases inherent in retrospective cohort studies. Specifically, we set the protocol a priori and undertook data collection by trained abstractors using a piloted data collection tool and a set of procedures and definitions. We made a significant effort to ensure complete data abstraction with multiple data sources. These efforts led to our ability to gather robust data that allowed for controlled analyses that have limited other studies.

Our study is not without limitation, however. We cannot eliminate all of the inherent potential biases. Although we were successful in obtaining modified Fisher grades for the majority of patients, the documenting of other prognostic scales was poor, limiting our ability to use these data in our models. We applied very stringent and conservative diagnostic criteria for vasospasm, as a measure of $\mathrm{DCI}$, that included the need for imaging, clinical change, and treatment initiation. Owing to variances and inadequacies in the documentation, we believe that our finding of a vasospasm incidence of $26.9 \%$ is a significant underestimation of the true incidence. As such, this may have precluded our ability to demonstrate vasospasm as an important predictor of RBC transfusion, both overall and in the anemia subgroups. Further, we were unable to collect undocumented factors that may have led to the decision to transfuse a patient to the extent that it is unclear if or to what degree a single $\mathrm{Hb}$ value influenced the decision. Last, as we studied a retrospective cohort, we were limited to measuring outcome at hospital discharge because 6- or 12-month follow-up was not ascertained. It is clear that recovery from aSAH occurs over months and even years, and this shorter follow-up may bias toward worse outcome [30,31].

\section{Conclusions}

Our study suggests that current practice includes a restrictive transfusion strategy and that RBC transfusion in this cohort of patients was not associated with a worse outcome when controlling for other important factors. Rigorous randomized controlled trials to better understand the role and timing of RBC transfusion in this patient population are still needed.

\section{Additional file}

Additional file 1: Supplemental methods: expanded definitions. Supplemental data: oral anticoagulant data. Figure S1. Anemia (hemoglobin, $\leq 100 \mathrm{~g} / \mathrm{L}$ ) rates across centers. Figure S2. RBC transfusion rates across centers. (DOCX $70 \mathrm{~kb}$ )

\section{Abbreviations}

aSAH: Aneurysmal subarachnoid hemorrhage; CT: Computed tomography; DCl: Delayed cerebral ischemia; GCS: Glasgow Coma Scale; Hb: Hemoglobin; ICU: Intensive care unit; mRS: Modified Rankin Scale; PEG: Percutaneous gastrostomy tube; PRBCs: Packed red blood cells; RBC: Red blood cell

\section{Acknowledgements}

We acknowledge the significant contributions to this work by our late colleague and friend Dr. Cheemun Lum. The authors also acknowledge the tremendous efforts of ICU research coordinators Irene Watpool, Denise Foster, Marie-Claude Tremblay and Caroline Leger. Thank-you to Drs. V. McCredie and D. Scales from the Canadian Critical Care Trials Group for their thorough and critical review of the manuscript.

\section{Funding}

This work was completed with the support of a competitive peer-reviewed seed grant from the departments of medicine and critical care at the University of Ottawa (Ottawa, ON, Canada).

\section{Availability of data and materials}

The data that support the findings of this study are available from the corresponding author upon reasonable request.

\section{Authors' contributions}

SWE, LM, and DF came up with the study concept. SWE, LM, DF, MC, AFT, FL, $D G, A G, A T, G P, R M$, and $A B$ developed the study design and protocol. SWE, MC, AFT, FL, DG, AG, KM, RC, RDC, RZ, CVW, JS and AD collected data. SWE, LM, MC, and RM performed analysis. SWE prepared the first draft of the manuscript. All coauthors provided input and critical review of the manuscript leading to the final version. All authors read and approved the final manuscript.

\section{Ethics approval and consent to participate}

This study was approved by the Ottawa Health Sciences Network Research Ethics Board (no. 20140349-01H) as well as ethics committees each participating center, which waived the need for informed consent.

Consent for publication

Not applicable.

Competing interests

The authors declare that they have no competing interests.

\section{Publisher's Note}

Springer Nature remains neutral with regard to jurisdictional claims in published maps and institutional affiliations.

\section{Author details}

${ }^{1}$ Department of Medicine (Critical Care), The Ottawa Hospital, Civic Campus Room F202, 1053 Carling Avenue, Ottawa, ON K1Y 4E9, Canada. ${ }^{2}$ Clinical Epidemiology Program (Centre for Transfusion Research), Ottawa Hospital Research Institute, Ottawa, ON, Canada. ${ }^{3}$ Department of Medicine, University of Montreal, Montreal, QC, Canada. ${ }^{4}$ Department of Anesthesiology \& Critical Care, Université Laval, Quebec City, QC, Canada. ${ }^{5}$ Department of Medicine, Université Laval, Quebec City, QC, Canada. ${ }^{6}$ Deparment of Anesthesiology, Pharmacology \& Therapeutics, University of British Columbia, Vancouver, BC, Canada. ${ }^{7}$ Department of Medicine, University of Manitoba, Winnipeg, MB, Canada. ${ }^{8}$ Department of Medicine, University of Ottawa, Ottawa, ON, Canada. ${ }^{9}$ Department of Medicine, University of Saskatchewan, Regina, SK, Canada. ${ }^{10}$ Department of Surgery (Neurosurgery), University of Ottawa, Ottawa, ON, Canada. ${ }^{11}$ Department of Social and Preventive Medicine, Université Laval, 
Quebec City, QC, Canada. ${ }^{12}$ Department of Surgery, University of Ottawa, Ottawa, ON, Canada.

Received: 15 January 2018 Accepted: 7 June 2018 Published online: 04 July 2018

\section{References}

1. Diringer MN, Bleck TP, Claude Hemphill J, Menon D, Shutter L, Vespa P, et al. Critical care management of patients following aneurysmal subarachnoid hemorrhage: recommendations from the Neurocritical Care Society's multidisciplinary consensus conference. Neurocrit Care. 2011;15:211-40

2. Bederson JB, Connolly ES, Batjer HH, Dacey RG, Dion JE, Diringer MN, et al. Guidelines for the management of aneurysmal subarachnoid hemorrhage: a statement for healthcare professionals from a special writing group of the Stroke Council, American Heart Association. Stroke. 2009;40:994-1025.

3. Connolly ES, Rabinstein AA, Carhuapoma JR, Derdeyn CP, Dion J, Higashida RT, et al. Guidelines for the management of aneurysmal subarachnoid hemorrhage: a guideline for healthcare professionals from the American Heart Association/American Stroke Association. Stroke. 2012:43:1711-37.

4. Sampson TR, Dhar R, Diringer MN. Factors associated with the development of anemia after subarachnoid hemorrhage. Neurocrit Care. 2010;12:4-9.

5. Kramer AH, Gurka MJ, Nathan B, Dumont AS, Kassell NF, Bleck TP. Complications associated with anemia and blood transfusion in patients with aneurysmal subarachnoid hemorrhage. Crit Care Med. 2008;36:2070-5.

6. Le Roux PD. Anemia and transfusion after subarachnoid hemorrhage. Neurocrit Care. 2011;15:342-53.

7. Naidech AM, Shaibani A, Garg RK, Duran IM, Liebling SM, Bassin SL, et al. Prospective, randomized trial of higher goal hemoglobin after subarachnoid hemorrhage. Neurocrit Care. 2010;13:313-20.

8. Leal-Noval SR, Arellano-Orden V, Muñoz-Gómez M, Cayuela A, MarínCaballos A, Rincón-Ferrari MD, et al. Red blood cell transfusion guided by near infrared spectroscopy in neurocritically ill patients with moderate or severe Anemia: a randomized, controlled trial. J Neurotrauma. 2017:34:2553-9.

9. Kramer A. Hemoglobin thresholds for a clinical trial comparing liberal and restrictive transfusion strategies in patients with aneurysmal subarachnoid hemorrhage: a multidisciplinary North American survey [abstract]. Neurocrit Care. 2010;13(Suppl 1):S207.

10. Lacroix J, Hébert PC, Hutchison JS, Hume HA, Tucci M, Ducruet T, et al. Transfusion strategies for patients in pediatric intensive care units. $\mathrm{N}$ Engl J Med. 2007:356:1609-19.

11. Hébert PC, Wells G, Blajchman MA, Marshall J, Martin C, Pagliarello G, et al. A multicenter, randomized, controlled clinical trial of transfusion requirements in critical care. Transfusion Requirements in Critical Care Investigators, Canadian Critical Care Trials Group. N Engl J Med. 1999:340:409-17.

12. Østbye T, Levy AR, Mayo NE. Hospitalization and case-fatality rates for subarachnoid hemorrhage in Canada from 1982 through 1991: the Canadian Collaborative Study Group of Stroke Hospitalizations. Stroke. 1997:28:793-8.

13. Kramer AH, DA Z, Bleck TP, Dumont AS, Kassell NF, Nathan B. Relationship between hemoglobin concentrations and outcomes across subgroups of patients with aneurysmal subarachnoid hemorrhage. Neurocrit Care. 2009;10:157-65.

14. Hunt WE, Hess RM. Surgical risk as related to time of intervention in the repair of intracranial aneurysms. J Neurosurg. 1968;28:14-20.

15. World Federation of Neurological Surgeons. Report of World Federation of Neurological Surgeons Committee on a Universal Subarachnoid Hemorrhage Grading Scale. J Neurosurg 1988:68:985-986.

16. Frontera JA, Claassen J, Schmidt JM, Wartenberg KE, Temes R, Connolly ESJ, et al. Prediction of symptomatic vasospasm after subarachnoid hemorrhage: the modified Fisher scale. Neurosurgery. 2006;58:21-7.

17. Carson JL, Terrin ML, Noveck H, Sanders DW, Chaitman BR, Rhoads GG, et al. Liberal or restrictive transfusion in high-risk patients after hip surgery. $\mathrm{N}$ Engl J Med. 2011;365:2453-62.

18. Murphy GJ, Pike K, Rogers CA, Wordsworth S, Stokes EA, Angelini GD, et al. Liberal or restrictive transfusion after cardiac surgery. N Engl J Med. 2015:372:997-1008.

19. Hajjar LA, Vincent JL, Galas FRBG, Nakamura RE, Silva CMP, Santos MH, et al. Transfusion requirements after cardiac surgery: the TRACS randomized controlled trial. JAMA. 2010;304:1559-67.
20. Dankbaar JW, Slooter AJ, Rinkel GJ, Schaaf IC. Effect of different components of triple-H therapy on cerebral perfusion in patients with aneurysmal subarachnoid haemorrhage: a systematic review. Crit Care. 2010;14:R23.

21. Kramer AH, Diringer MN, Suarez JI, Naidech AM, Macdonald LR, Le Roux PD. Red blood cell transfusion in patients with subarachnoid hemorrhage: a multidisciplinary North American survey. Crit Care. 2011;15:R30.

22. Kumar MA, Boland TA, Baiou M, Moussouttas M, Herman JH, Bell RD, et al. Red blood cell transfusion increases the risk of thrombotic events in patients with subarachnoid hemorrhage. Neurocrit Care. 2014;20:84-90.

23. Naidech AM, Drescher J, Ault ML, Shaibani A, Batjer HH, Alberts MJ. Higher hemoglobin is associated with less cerebral infarction, poor outcome, and death after subarachnoid hemorrhage. Neurosurgery. 2006;59:775-9.

24. Smith MJ, Le Roux PD, Elliott JP. Winn HR. Blood transfusion and increased risk for vasospasm and poor outcome after subarachnoid hemorrhage. J Neurosurg. 2004;101:1-7.

25. Matsushima K, Eastman A, Shafi S, Burris A, Tyner T, Frankel H. Transfusion increases infection without affecting neurologic outcome in spontaneous subarachnoid hemorrhage [abstract]. Crit Care. 2009;13(Suppl 1):P100

26. Festic E, Rabinstein AA, Freeman WD, Mauricio EA, Robinson MT, Mandrekar J, et al. Blood transfusion is an important predictor of hospital mortality among patients with aneurysmal subarachnoid hemorrhage. Neurocrit Care. 2013:18:209-15.

27. Broessner G, Lackner P, Hoefer C, Beer R, Helbok R, Grabmer C, et al. Influence of red blood cell transfusion on mortality and long-term functional outcome in 292 patients with spontaneous subarachnoid hemorrhage. Crit Care Med. 2009;37:1886-92.

28. Festic E, William F, Rabinstein A, Gajic O. Blood transfusion is a predictor of hospital mortality in aneurysmal subarachnoid hemorrhage [abstract]. Crit Care Med. 2010;38(12 Suppl):A90.

29. Festic E, Rabinstei AA, Freema WD, Dupon SA, Robinso MT, Diverti GD, et al Association of anemia and blood transfusion with the outcome of patients with aneurysmal subarachnoid hemorrhage [abstract 0390]. Intensive Care Med. 2010:36(Suppl 2):S183.

30. Ogden J, Utley T, Mee E. Neurological and psychosocial outcome 4 to 7 years after subarachnoid hemorrhage. Neurosurgery. 1997:41:25-34.

31. Navi BB, Kamel H, Hemphill JC, Smith WS. Trajectory of functional recovery after hospital discharge for subarachnoid hemorrhage. Neurocrit Care. 2012;17:343-7.

\section{Ready to submit your research? Choose BMC and benefit from:}

- fast, convenient online submission

- thorough peer review by experienced researchers in your field

- rapid publication on acceptance

- support for research data, including large and complex data types

- gold Open Access which fosters wider collaboration and increased citations

- maximum visibility for your research: over $100 \mathrm{M}$ website views per year

At BMC, research is always in progress.

Learn more biomedcentral.com/submissions 